1. Dip. Card, MD (Cardiology) Consultant Cardiologist Liaquat University Hospital Hyderabad / Jamshoro

2. FCPS

Associate Professor Department of Cardiology Liaquat University of Medical and Health Sciences (LUMHS), Jamshoro, Pakistan

3. FCPS

Assistant Professor

Department of Medicine unit-I

Liaquat University Hospital Hyderabad / LUMHS, Jamshoro, Sindh Pakistan

4. Postgraduate Resident

Department of Medicine

Liaquat University Hospital Hyderabad / LUMHS, Jamshoro, Sindh Pakistan

5. Final year MBBS

Shaheed Mohtarma Benazir Bhutto Medical University (SMBBMU) Larkana

6. Final year MBBS

Shaheed Mohtarma Benazir Bhutto

Medical University (SMBBMU)

Larkana

Department of Medicine

Liaquat University Hospital Hyderabad / LUMHS,

Jamshoro, Sindh Pakistan

Correspondence Address: Dr. Syed Zulfiquar Ali Shah House No: 279, Doctor's Colony Hirabad, Hyderabad, Sindh, Pakistan Cell \#: 0300-3057155

zulfikar229@hotmail.com

Article received on:

$17 / 11 / 2015$

Accepted for publication:

10/02/2016

Received after proof reading: 04/05/2016

\section{ACUTE ISCHEMIC STROKE; ELECTROCARDIOGRAPHIC AND ECHOCARDIOGRAPHIC FINDINGS IN PATIENTS. (POTENTIAL SOURCE OF CARDIAC EMBOLI)}

\author{
Dr. Mashooq Ali Dasti ${ }^{1}$, Dr. Syed Fasih Ahmed Hashmi², Dr. Mukhtiar Hussain Jaffery ${ }^{3}$, \\ Dr. Hamid Nawaz Ali Memon ${ }^{4}$, Dr. Athar Hussain Memon ${ }^{5}$, Dr. Arshad Maqbool Jalbani ${ }^{6}$, \\ Dr. Syed Zulfiquar Ali Shah
}

ABSTRACT... Objectives: To determine the electrocardiographic and echocardiographic findings in patients with acute ischemic stroke (potential source of cardiac emboli). Study Design: Cross section descriptive study. Period: Six months. Setting: Liaquat University Hospital Hyderabad. Patients and Methods: The subjects with history and clinical features suggestive of cerebrovascular accident (CVA). After establishing the diagnosis of acute ischemic stroke the electrocardiography (ECG) was advised and those subjects had abnormal findings on ECG were went for echocardiography to evaluate the specific cause related to acute ischemic stroke. The two-dimensional and M-mode echocardiography was performed by consultant cardiologist had $\geq$ five years experienced in echocardiography because echocardiographic study in patients with cerebrovascular accident (confirmed on CT scan) is evidence of potential cardiac abnormalities as a predisposing cause for the vascular event. The data was collected on pre-designed proforma and was analyzed in SPSS 16 and the frequency and percentage was calculated. Results: Total one hundred patients with acute ischemic stroke were studied for electrocardiographic and echocardiographic findings during six months study period. The mean \pm SD for age of patients with acute ischemic stroke was $43.67 \pm 10.62$. Majority of the patients were males and $69 \%$ while the age and gender cross tabulation was also statistically significant $(p=0.03)$. The electrocardiographic abnormalities were indentified in $80 \%$ patients (AF in $16.2 \%$, LVH in $22.5 \%$, LBBB in $10 \%$, wide QRS complex in $10 \%$ and ischemic changes in $8.7 \%$ ) while the echocardiographic abnormalities were detected in $70 \%$ patients of which global hypokinesia (28.5\%), LVH (25.7\%) and diastolic dysfunction (17.14)\% were predominant. Conclusion: The cardiac embolic source is the major cause for acute ischemic stroke and detected by echocardiography as it is the main tool in diagnosing the source of embolus.

Key words: Hyperhomocysteinemia, Homocysteine, Homocysteinemia and ischemic heart diseases.

Article Citation: Dasti MA, Hashmi SFA, Jaffery MH, Memon HNA, Memon AH, Jalbani AM, Shah SZA. Acute ischemic stroke; electrocardiographic and echocardiographic findings in patients. (potential source of cardiac emboli). Professional Med $\mathrm{J}$ 2016;23(5):535-538.. DOI: 10.17957/TPMJ/16.3180

\section{INTRODUCTION}

The sudden and rapidly developing symptoms and /or signs of focal or global disturbance of cerebral function lasting $>24$ hours or leading to death with no cause other than vascular origin is labeled as stroke / cerebrovascular accident and considered as the main culprit of morbidity and mortality worldwide. ${ }^{1}$ The stroke is either due to cerebral infarction or haemorrhage, although ischaemic cerebral infarction has more frequently observed in majority of the population. ${ }^{2}$ The ischaemia may be due to vascular obstruction because of disease process related to carotid and intracranial vascular system or may be because of coexisting cardiac diseases leads to embolic phenomenon. ${ }^{3-5}$ Invasive cardiological procedure has great importance irrespective of neurological ischaemic episodes while appropriate and specific medical management can be helpful to improve morbidity and mortality. ${ }^{6,7}$ The various cardiovascular adverse events has been reported formerly in the stroke patients and considered them as the root cause of the cerebrovascular accidents. ${ }^{8,9}$

Therefore this study was conducted to evaluate the causative potential cardiac abnormalities observed in patients presenting with acute ischemic stroke, as early diagnosis and effective measure can save the patient to acquire various life 
threatening complications due to cerebrovascular accidents.

\section{PATIENTS AND METHODS}

The cross section descriptive study of six months was conducted at Liaquat University Hospital Hyderabad on the subjects with history and clinical features suggestive of cerebrovascular accident (CVA). The patients presented with the neurological symptoms i.e. weakness, involuntary movements, cranial nerve lesion, alterted senosorium, aphasia, seizure and sensory deficit were recruited and enrolled in the study. The informed consent was taken from every patients / attendants of the patients for the participation in the study while the detailed history was taken from patient or their attendants and clinical evaluation examination was done, the routine investigations were advised and the acute ischemic stroke was diagnosed by advising the CT scan brain. After establishing the diagnosis of acute ischemic stroke the electrocardiography (ECG) was advised and those subjects had abnormal findings on ECG were went for echocardiography to evaluate the specific cause related to acute ischemic stroke. The exclusion criteria of the study were intracerebral haemorrhage, congenital heart diseases, venous infarctions and rheumatic heart disease. The major and specific abnormalities on ECG were assessed i.e. (a) ischaemic heart disease by ECG criteria i.e. pathological $Q$ waves or existence of QS components, elevation of ST segment $>1 \mathrm{~mm}$ and inverted, symmetrical and deep T waves, (b) the LVH by Romhilt Estes scoring system, (c) LBBB by presence of prolonged QRS duration, RsR complex in aVL or RR or M components in LI, V5, V6. (d) RBBB by $\mathrm{S}$ wave in LI, V5 and V6 and wide notched, tall $\mathrm{R}$ wave in $\mathrm{V} 1$. The two-dimensional and M-mode echocardiography was performed by consultant cardiologist had $\geq$ five years experienced in echocardiography because echocardiographic study in patients with cerebrovascular accident (confirmed on CT scan) is evidence of potential cardiac abnormalities as a predisposing cause for the vascular event. The data was collected on pre-designed proforma and then analyzed in SPSS. The frequency and percentage (\%) and the mean $\pm S D$ were calculated. The stratification was done for age and gender in subjects with ischemic stroke. The chi-square test was applied (age and gender) and the statistical significance was considered by $p$-value $\leq 0.05$.

\section{RESULTS}

Total one hundred patients with acute ischemic stroke were studied for electrocardiographic and echocardiographic findings during six months study period. The mean $\pm S D$ for age of patients with acute ischemic stroke was $43.67 \pm 10.62$. The age in context to sex and ECG and ECHO findings is shown in Table I-III. The common presenting clinical features observed in the study population were weakness $93 \%$, cranial nerve lesions $82 \%$, altered sensorium and aphasia $89 \%$, seizures $75 \%$, sensory disturbance in $78 \%$, involuntary movements in $72 \%$ and multiple clinical features in $76 \%$. Regarding CT scan the anterior cerebral circulation involved in $30 \%$ patients, middle cerebral artery in $60 \%$ patients and posterior cerebral circulation in $10 \%$ subjects whereas in context to the demographic distribution majority of the subjects belonged to rural areas. The electrocardiographic changes were observed in $80 / 100$ (80\%) subjects whereas echocardiographic findings were detected in $70 / 80(87.5 \%)$ patients with acute ischemic stroke.

\begin{tabular}{|c|c|c|c|c|c|}
\hline & & \multicolumn{2}{|c|}{ GENDER } & \multirow[t]{2}{*}{ Total } & \multirow[t]{2}{*}{ P-value } \\
\hline & & Male & Female & & \\
\hline \multirow{6}{*}{ AGE } & $20-29$ & 2 (28.6\%) & 5 (71.4\%) & 7 (100.0\%) & \\
\hline & $30-39$ & 10 (50.0\%) & $10(50.0 \%)$ & 20 (100.0\%) & \\
\hline & $40-49$ & 17 (77.3\%) & $5(22.7 \%)$ & 22 (100.0\%) & $0.03 *$ \\
\hline & $50-59$ & $19(79.2 \%)$ & 5 (20.8\%) & 24 (100.0\%) & \\
\hline & $60-69$ & 15 (83.3\%) & $3(16.7 \%)$ & 18 (100.0\%) & \\
\hline & $70+$ & 6 (66.7\%) & 3 (33.3\%) & 9 (100.0\%) & \\
\hline Total & & 69 (69.0\%) & 31 (31.0\%) & 100 (100.0\%) & \\
\hline
\end{tabular}




\begin{tabular}{|l|c|c|}
\hline \multicolumn{1}{|c|}{ FINDINGS } & N $=\mathbf{8 0}$ & (\%) \\
\hline Atrial fibrillation & 13 & 16.25 \\
\hline Left ventricular hypertrophy & 18 & 22.5 \\
\hline Left bundle branch block & 08 & 10 \\
\hline Right bundle branch block & 02 & 2.5 \\
\hline Wide QRS complex & 08 & 10 \\
\hline Left axis Deviation & 02 & 2.5 \\
\hline Right axis Deviation & 03 & 3.75 \\
\hline Prolonged QT interval & 02 & 2.5 \\
\hline Premature ventricular beats & 05 & 6.25 \\
\hline Ischemic heart disease & 07 & 8.75 \\
\hline Multiple findings & 12 & 15 \\
\hline \multicolumn{2}{|c|}{ Table-II. Electrocardiographic Findings in Patients } \\
with Acute Ischemic Stroke \\
\hline
\end{tabular}

\begin{tabular}{|l|c|c|}
\hline \multicolumn{1}{|c|}{ DISORDER } & N $=\mathbf{7 0}$ & (\%) \\
\hline Global hypokinesia & 20 & 28.57 \\
\hline Left ventricular hypertrophy & 18 & 25.71 \\
\hline Mitral regurgitation & 03 & 4.28 \\
\hline Diastolic dysfunction & 12 & 17.14 \\
\hline Systolic dysfunction. & 08 & 11.42 \\
\hline Cardiomyopathy & 03 & 4.28 \\
\hline Multiple abnormalities & 06 & 8.57 \\
\hline Table-III. Echocardiographic Findings in Patients with \\
\hline \multicolumn{2}{|c|}{ Acute Ischemic Stroke } \\
\hline
\end{tabular}

\section{DISCUSSION}

In this study, an echocardiographic assessment was done for subjects with abnormal ECG findings, of which $70 / 80(87.5 \%)$ had abnormalities on echocardiography while 10/80 (12.5\%) patients had normal echocardiograph. The abnormalities are potential cardio embolic source detected by echocardiography. Most common abnormalities found were global hypokinesia $28.5 \%$ followed by left ventricular hypertrophy $25.7 \%$, diastolic dysfunction $17.1 \%$, systolic dysfunction $11.4 \%$ and mitral regurgitation $4.2 \%$. The observations are consistent to the study by Uma $\mathrm{N}$ et al, ${ }^{10}$ in which potential cardio embolic source was found in 27 (54\%) patients and common abnormalities detected were left ventricular wall hypokinesia in $13(26 \%)$ followed by mitral regurgitation in 9 $(18 \%)$ and cardiomyopathy in 7 (14\%) patients. Zenkers, et al ${ }^{11}$ identified potential cardio embolic source in fifty percent patients by transthoracic echocardiography also consistent with present study. However, Gagliardi R, et al. ${ }^{12}$ reported potential cardio embolic source in $33 \%$ in young study population, while in present series, the mean age $\pm S D$ of the study population was $43.67 \pm 10.62$. The cerebral embolism responsible for cerebral infarction in $23.5 \%$ subjects in the study by. Caplan LR. ${ }^{13}$ The atrial fibrillation, coronary artery and valvular cardiac disease, cardiomyopathy and mitral calcification were reported the common etiologies. Echocardiographic abnormalities in patients with acute ischemic stroke include left ventricular global hypokinesia, left ventricular hypertrophy, calcified aortic valve; mitral regurgitation and mitral annulus calcification were reported by Uma $\mathrm{N}^{10}$ and Caplan et al. ${ }^{13}$

In current series subjects with clinical and ECG evidence of cardiac disease as many as $87.5 \%$ noted to had a potential cardiac embolic source. Similar findings were reported by Zenker. ${ }^{11}$ The higher figures were also observed by Cujec et al. ${ }^{14}$ In current series left ventricular hypertrophy was observed in $25.7 \%$ patients. This is comparable to study conducted by Marco R et al.98 The lower figures $(12 \%)$ were identified by Uma $\mathrm{N},{ }^{10}$ while Cujec $\mathrm{B}$, et al ${ }^{14}$ observed that $\mathrm{LVH}$ is independent risk factor for stroke.

\section{CONCLUSION}

The ischemic brain attacks are major cause of morbidity and mortality and the incidence increases with the advancement of age. The cardiac embolic source is the major cause for acute ischemic stroke and detected by echocardiography as it is the main tool in diagnosing the source of cardiac embolus.

Copyright(C) 10 Feb, 2016.

\section{REFERENCES}

1. Feigin $\mathrm{VL}$, Forouzanfar $\mathrm{MH}$, Krishnamurthi $\mathrm{R}$, Mensah GA, Connor M, Bennett DA, et al. Global and regional burden of stroke during 1990-2010: findings from the Global Burden of Disease Study 2010. Lancet.2014; 383(9913):245-54.

2. Baldwin K, Orr S, Briand M, Piazza C, Veydt A, McCoy $\mathrm{S}$. Acute ischemic stroke update. Pharmacotherapy. 2010; 30(5):493-514. 
3. Onwuekwe IO, Ezeala-Adikaibe B. Ischemic Stroke and Neuroprotection. Ann Med Health Sci Res.2012; 2(2):186-90.

4. Mackay MT, Wiznitzer M, Benedict SL, Lee KJ, Deveber GA, Ganesan V, et al. Arterial ischemic stroke risk factors: the International Pediatric Stroke Study. Ann Neurol.2011; 69(1):130-40.

5. Kamal AK, Khealani BA, Ansari SA, Afridi M, Syed NA. Early ischemic stroke presentation in Pakistan. Can J Neurol Sci.2009; 36(2):181-6.

6. Khealani BA, Khan M, Tariq M, Malik A, Siddiqi AI, Awan $S$, et al. Ischemic strokes in Pakistan: observations from the national acute ischemic stroke database. J Stroke Cerebrovasc Dis.2014; 23(6):1640-7.

7. Ronning OM. Very long-term mortality after ischemic stroke: predictors of cardiovascular death. Acta Neurol Scand Suppl. 2013; (196):69-72.

8. Palazzuoli A, Ricci D, Lenzi C, Lenzi J, Palazzuoli V. Transesophageal echocardiography for identifying potential cardiac sources of embolism in patients with stroke. Neurol Sci.2000; 21(4):195-202.
9. Bogousslavsky J, Cachin C, Regli F, Despland PA, Van Melle G, Kappenberger. Cardiac sources of embolism and cerebral infarction--clinical consequences and vascular concomitants: the Lausanne Stroke Registry. Neurology.1991; 41(6):855-9.

10. Uma N. Echocardiography in patients with cerebral infarction JAPI 1999; 47:291-93.

11. Zenker. Transesophageal echocardiography in young patients with cerebral ischaemic events. Stroke.1988; 9:345-48.

12. Gagliardi R, Benvenuti L, Frosini F, Ammannati F, Barletta GA, Fantini F. Frequency of echocardiographic abnormalities in patients with ischaemia of the carotid territory - a preliminary report. Stroke 1985; 16 (1): 118-121.

13. Caplan LR, Hier DB, D'Cruz I. Cerebral embolism in the Michael Reese Stroke Registry. Stroke.1983; 14:530-36.

14. Cujec B, Polasek P, Voll C, Shuaib A. Transesophageal echocardiography in detection of potential cardiac source of embolism in stroke patients. Stroke 1991; 22: 727-733.

\section{PREVIOUS RELATED STUDY}

Mozzam Ali Atif, ISCHAEMIC STROKE; ROLE OF CAROTID DOPPLER (Original) Prof Med Jour 14(3) 448-453 Jul, Aug, Sep, 2007.

\section{AUTHORSHIP AND CONTRIBUTION DECLARATION}

\begin{tabular}{|c|c|}
\hline Sr. \# & \multicolumn{1}{|c|}{ Author-s Full Name } \\
\hline 1 & Dr. Mashooq Ali Dasti ${ }^{1}$, \\
\hline 3 & Dr. S. Fasih Ahmed Hashmi \\
\hline 4 & Dr. Mukhtiar Hussain Jaffery \\
5 & Dr. Athar Hussain Memon \\
6 & Dr. Arshad Maqbool Jalbani \\
7 & Dr. Syed Zulfiquar Ali Shah \\
\hline
\end{tabular}

Contribution to the paper

Contribution to conception and design, acquisition of data, analysis and interpretation of data. Drafting the article and ashares the expert research opinion and expenence in finalizing the manuscript

Contributed in conception and interpretation of data and give his expert view for manuscript designing.

Analysis and interpretation of data contributed in conception and shares its expert research opinion Drafting, interpreting and analysis the data

Drafting and data collection

Analysis and manupulate the data and drafting

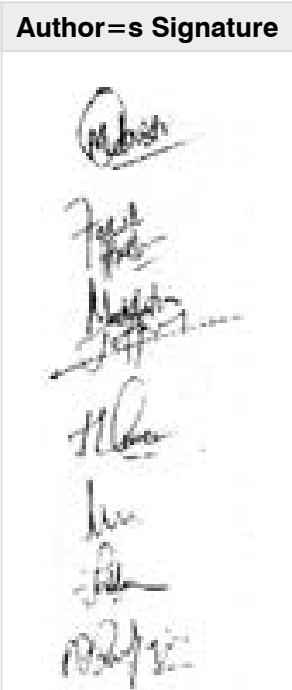

